\title{
Stability of green tea nanoscale zero-valent iron
}

\author{
Tomasz Suponik ${ }^{1, a}$, Marcin Lemanowicz ${ }^{2}$, and Pawel Wrona ${ }^{1}$ \\ ${ }^{1}$ Silesian University of Technology, Faculty of Mining and Geology,44-100 Gliwice ul. Akademicka 2, Poland \\ ${ }^{2}$ Silesian University of Technology, Faculty of Chemistry, 44-100 Gliwice ul. Strzody 7, Poland
}

\begin{abstract}
Colloidal suspension of nano zero-valent iron (nZVI), obtained as a result of mixing green tea (GT) solution with iron solutions $\left(\mathrm{FeCl}_{2}\right.$ and $\mathrm{FeSO}_{4}$ separately to form two suspensions: GT-nZVI $\mathrm{FeCl}_{2}$ and GT-nZVI $\mathrm{FeSO}_{4}$ ) was assessed in terms of stability. The particles of suspensions had a tendency rapidly aggregation to form larger aggregates, and then settled. The absolute value of zeta potential $(\zeta)$ of suspensions did not exceed $17 \mathrm{mV}$. To prevent the aggregation of nZVI particles, the pHs were changed by the addition of $\mathrm{Na}_{2} \mathrm{CO}_{3}$ to obtain higher values of $\zeta$. For both suspensions, the zeta potential at a satisfactory level was obtained at $\mathrm{pH}$ values higher than 7.5. Then, the potential was lower than $-40 \mathrm{mV}$ for GT-nZVI $\mathrm{FeCl}_{2}$ and lower than $-25 \mathrm{mV}$ for GT-nZVI $\mathrm{Fes}_{\mathrm{F}}$. This means that the first suspension had a better stability than second. The isoelectric point (IEP) of GT-nZVI $\mathrm{FeCl}_{2}$ was in the range from 4.5 to 5 , while in the case of GT-nZVI ${ }_{\mathrm{FeSO} 4}$ all measured $\zeta$ were negative. To investigate the effect of increased ionic strength (IS) on the stability of suspensions at different $\mathrm{pH}$ values, $\mathrm{NaCl}$ and $\mathrm{MgSO}_{4}$ were added to the irons solutions. The final IS in the GT-nZVI was $12 \mathrm{mM}$. In both of the suspensions the absolute values of $\zeta$ were lower than previous and were about 25 and $20 \mathrm{mV}$, for GT-nZVI $\mathrm{FeCl}_{2}$ and GT-nZVI $\mathrm{FeSO}$, respectively.
\end{abstract}

\section{Introduction}

The application of zero-valent iron (nZVI) for the removal of heavy metals and halogenated organic compounds, as well as pesticides and herbicides is well established. Wastes resulting from the mining of non-ferrous metal ores and coal, as well as from the manufacturing process of non-ferrous metals accumulated at industrial waste disposal sites contain metal minerals and, as a result, may affect the quality of ground and surface waters in the southern provinces of Poland. Technical limitations [1] and the high cost of excavation in the case of deep construction have caused, that Wang and Zhang [2] proposed, to use $\mathrm{Fe}(0)$ as nano-sized particles. The suspension of nZVI is used for in situ remediation due to its large surface area, rapid reactivity and better injectability into aquifers [3]. An overview of techniques for nZVI production were presented in the article by Tosco et al. [4]. An effective, relatively cheap and environmentally friendly way of producing nZVI is the method of using green tea (GT) $[5,6]$. A key advantage of this method is its simplicity. GT-nZVI may be safely produced even outside the laboratory. Polyphenolic compound, tannic acid, determines the reducing properties of the tea [7].

${ }^{a}$ Corresponding author: tomasz.suponik@polsl.pl 
Besides the control of the reactivity of GT-nZVI, the important issues, that need to be analyzed for successful full-scale applications, are stability against aggregation. This study was carried out to obtain a high stability of GT-nZVI, in order to pump the suspension into correct places of the aquifer and remove contaminants.

\section{Materials and methods}

\subsection{Synthesis of GT-nZVI}

Nanoscale zero-valent iron particles was prepared in aqueous solutions by way of the reduction of ferrous iron Fe(II) using a solution of green tea (GT). The method was inspired by article written by Mystrioti et al. [6]. The 1:2 volume ratio of the GT solution-to-the Fe(II) solution were vigorously mixed in a flask reactor (see Fig. 1) at room temperature for an additional 15 minutes after the titration of GT. The solutions in the flask were mixed with a mechanical stirrer at $120 \mathrm{rpm}$. During titration at a rate of $1.0 \mathrm{~cm}^{3} / \mathrm{s}$, the solution of GT was introduced to reduce ferrous ions to zero-valent iron $\mathrm{Fe}(0)$.

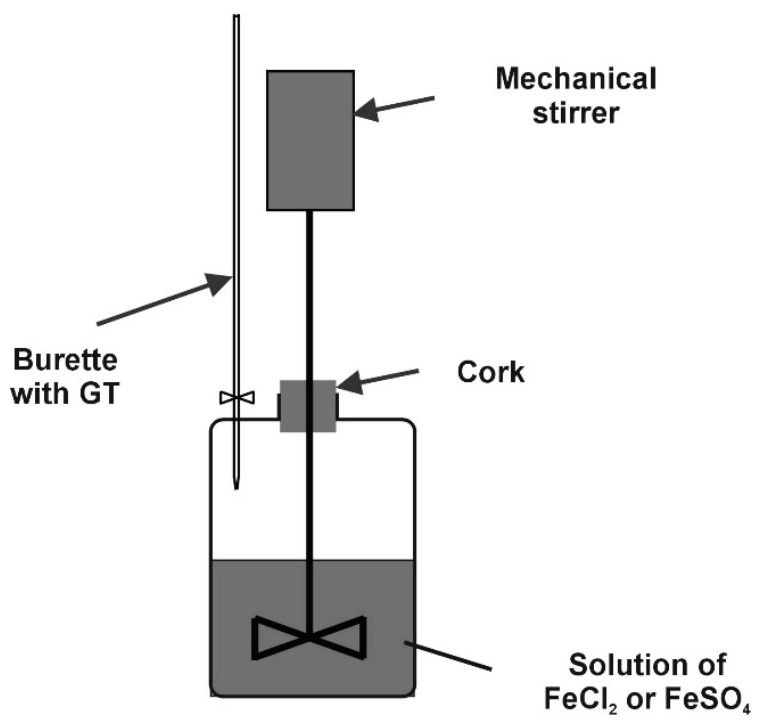

Figure 1. Laboratory set-up for GT-nZVI synthesis.

The Loyd brand of green tea was the source of polyphenolic compounds. An immersion of the dry green tea in deionized water at a temperature of $80-90^{\circ} \mathrm{C}$ for 30 minutes was the way of preparing the solution. It was filtered by the vacuum filtration, using a filter paper of $0.45 \mu \mathrm{m}$ pore size. The ratio of green tea leaves to deionized water amounted to $1.35 \mathrm{~g} / 50 \mathrm{ml}$, while the concentration of iron in the solutions varied depending on the experiment.

As a source of $\mathrm{Fe}(\mathrm{II})$, two chemicals were assessed at various concentrations. These were: $\mathrm{FeCl}_{2} \cdot 4 \mathrm{H}_{2} \mathrm{O}$ and $\mathrm{FeSO}_{4} \cdot \mathrm{H}_{2} \mathrm{O}$. Thus, the two nano-irons were finally tested: GT-nZVI $\mathrm{FeCl}_{2}$ and GT$\mathrm{nZVI}_{\mathrm{FeSO} 4}$. These chemicals were dissolved in deionized water for a short time before introducing the GT solution.

The $\mathrm{pH}$, conductivity and oxidation-reduction potential (ORP) in $\mathrm{FeCl}_{2}$ and $\mathrm{FeSO}_{4}$ solutions, as well as in the GT solution are presented in Table 1. The values shown in Table 1 were measured in appropriate solutions, which then formed the GT-nZVI suspensions, i.e. before mixing the solution of $\mathrm{Fe}(\mathrm{II})$ with the solution of GT. 
Table 1. $\mathrm{pH}$, conductivity, $\mathrm{ORP}$ in $\mathrm{FeCl}_{2}, \mathrm{FeSO}_{4}$ and GT solutions that later created GT- nZVI suspensions.

\begin{tabular}{|c|c|c|c|c|c|c|c|c|c|}
\hline \multirow{2}{*}{$\begin{array}{c}\text { Parameter, } \\
\text { unit }\end{array}$} & \multicolumn{4}{|c|}{$\begin{array}{l}\text { Solutions of } \mathrm{FeCl}_{2} \text { for the } \\
\text { preparation of GT-nZVI } \\
\text { containing: }\end{array}$} & \multicolumn{4}{|c|}{$\begin{array}{c}\text { Solutions of } \mathrm{FeSO}_{4} \text { for the } \\
\text { preparation of GT-nZVI } \\
\text { containing: }\end{array}$} & \multirow{2}{*}{$\begin{array}{c}\text { Solution } \\
\text { of GT }\end{array}$} \\
\hline & $\begin{array}{c}0.04 \mathrm{wt} \\
\% \mathrm{Fe}\end{array}$ & $\begin{array}{c}0.10 \mathrm{wt} \\
\% \mathrm{Fe}\end{array}$ & $\begin{array}{l}0.10 \mathrm{wt} \\
\% \mathrm{Fe} \\
\text { IS }\end{array}$ & $\begin{array}{c}0.15 \mathrm{wt} \\
\% \mathrm{Fe}\end{array}$ & $\begin{array}{c}0.04 \mathrm{wt} \\
\% \mathrm{Fe}\end{array}$ & $\begin{array}{c}0.10 \mathrm{wt} \\
\% \mathrm{Fe}\end{array}$ & $\begin{array}{l}0.10 \mathrm{wt} \\
\text { \%Fe } \\
\text { IS }\end{array}$ & $\begin{array}{c}0.15 \mathrm{wt} \\
\% \mathrm{Fe}\end{array}$ & \\
\hline $\mathrm{pH}$ & 2.41 & 2.22 & 2.18 & 2.09 & 2.98 & 2.66 & 2.63 & 2.46 & 6.19 \\
\hline Temperature, ${ }^{\circ} \mathrm{C}$ & 20.1 & 21.0 & 20.3 & 20.8 & 19.1 & 18.7 & 19.9 & 19.4 & 19.5 \\
\hline ORP, $\mathrm{mV}$ & 421 & 448 & 460 & 500 & 369 & 390 & 402 & 423 & 156 \\
\hline Cond., mS/cm & 2.20 & 5.07 & 5.93 & 6.38 & 1.31 & 2.23 & 2.73 & 2.91 & 0.76 \\
\hline
\end{tabular}

\subsection{Stability of GT-nZVI}

After formation of colloidal suspensions, it turned out that the GT-nZVI particles had a tendency to rapidly agglomerate forming larger aggregates due to the Van der Waals and magnetic forces, rendering them undeliverable to the targeted contaminant locations. The zeta potential is the major factor determining the stability of nanoparticles and mobility in aquifers. The absolute value of zeta potential of suspensions did not exceed $20 \mathrm{mV}$ (see Fig. 2). To prevent aggregation of nZVI particles the pHs were changed by the addition of $\mathrm{Na}_{2} \mathrm{CO}_{3}$ to obtain higher values of zeta potential, as shown in the paper by Suponik [8]. The chemical was added to the flask reactor directly after the preparation of the nZVI. The suspension was then mixed with a mechanical stirrer at $120 \mathrm{rpm}$ for 10 minutes.

To investigate the effect of increased ionic strength (IS) on the stability of suspensions, $\mathrm{NaCl}$ and $\mathrm{MgSO}_{4}$ were added in some experiments to the Fe solution, i.e. just before titration of the green tea. The final concentration of these chemical substances in the GT-nZVI, i.e. after the addition of GT, were $8 \mathrm{mM}$ and $1 \mathrm{mM}$, for $\mathrm{NaCl}$ and $\mathrm{MgSO}_{4}$, respectively. The final IS in the GT-nZVI was $12 \mathrm{mM}$.

The following parameters were analyzed in the study: zeta potential, $\mathrm{pH}$, ORP, temperature, conductivity, and finally a grain-size distribution of the particles in one chosen suspension. The measurements (except the measurement of particle size) began 10 minutes after the preparation of the samples. The $\mathrm{pH}$, conductivity, ORP and temperature were measured with the Knick PORTAMESS meters, while zeta potential and grain-size distribution were measured with a zeta-meter (Laser Zee PenKem Model 501) and a laser granulometer (Malvern Nano S-90), respectively.

\section{Results and discussion}

The zeta potential measurements as a function of $\mathrm{pH}$ are shown in Fig. 2. Results indicated that in both cases the $\mathrm{pH}$ above 7.5 corresponds to the maximum suspension stability of GT-nZVI. For measurements with a higher ionic strength of GT-nZVI the zeta potential was ca. $-25 \mathrm{mV}$, while in other cases, this was lower than $-40 \mathrm{mV}$ for GT-nZVI $\mathrm{FeCl}_{2}$ and lower than $-25 \mathrm{mV}$ for GT$\mathrm{nZVI}_{\mathrm{FeSO} 4}$, which means that the suspensions had good stability. Thus, the addition of $\mathrm{Na}_{2} \mathrm{CO}_{3}$ caused a significant increase in the stability of the GT-nZVI. 

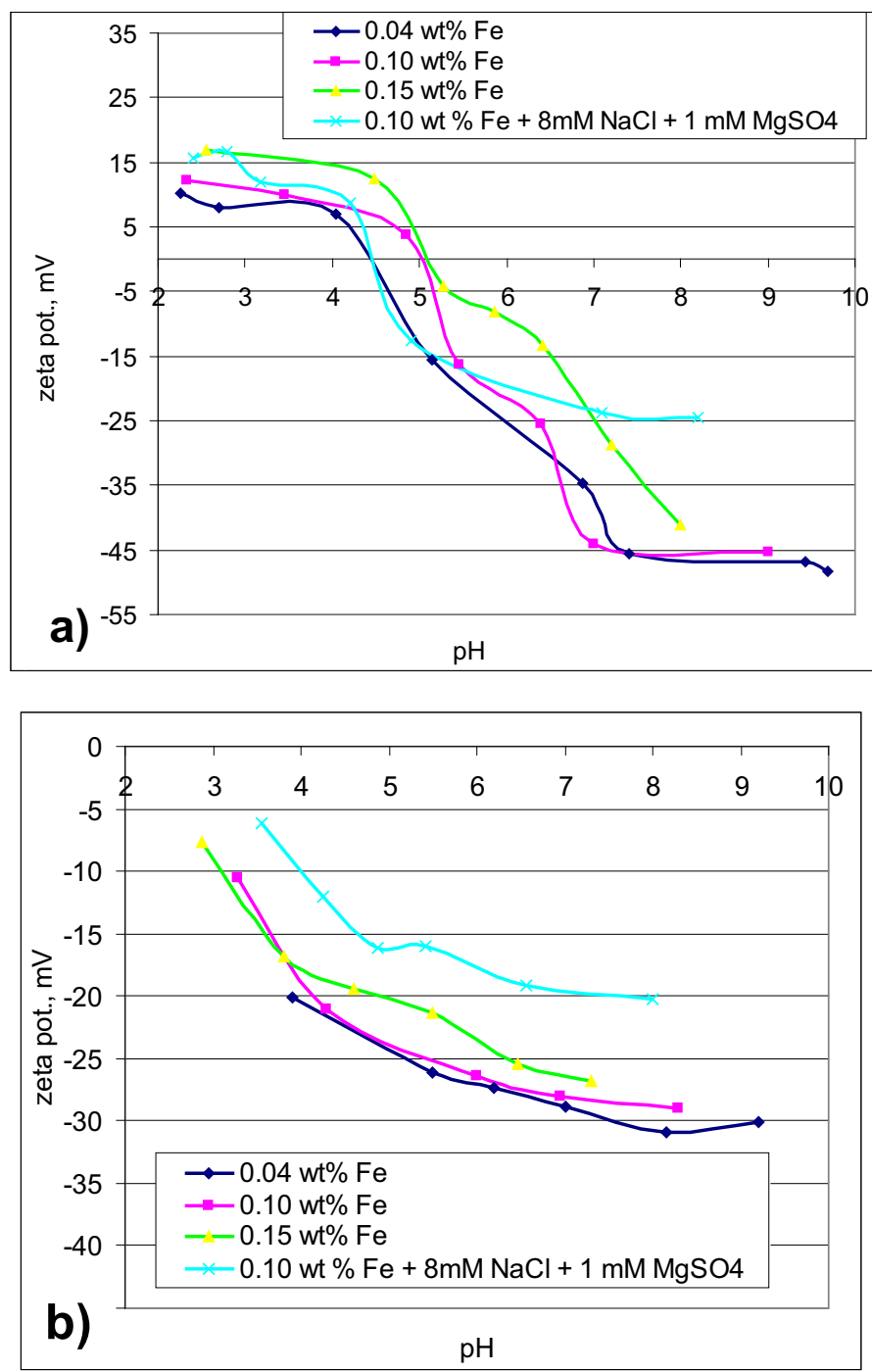

Figure 2. Zeta potential of GT-nZVI as a function of $\mathrm{pH}$ for: a) GT- nZVI $\mathrm{FeCl}_{2}$, b) GT- nZVI $\mathrm{FeSO}_{\mathrm{F}}$.

When particles have low absolute zeta potential values, then flocculation process occurs. This was noticeable macroscopically for all the samples having a $\mathrm{pH}$ lower than 5.5. The isoelectric point (IEP) in the presented study for GT-nZVI $\mathrm{FeCl}_{2}$ was in the range from 4.5 to 5 . In the case of the second suspension, all measured zeta potentials were negative. The trends indicate that the IEP was then 2.5.

As provided by Ji [9] and Sun et al. [10] the IEP was found to be between 8.0 and 8.5. In both cases, the sodium borohydride was applied as a reducer. Comparatively, the values of IEP for typical products formed on the surface of the $\mathrm{Fe}(0)$, such as the $\alpha-\mathrm{FeO}(\mathrm{OH}), \gamma-\mathrm{FeO}(\mathrm{OH}), \mathrm{Fe}^{2+} \mathrm{Fe}^{3+}{ }_{2} \mathrm{O}_{4}$, $\mathrm{Fe}_{2} \mathrm{O}_{3}, \mathrm{Fe}(\mathrm{OH})_{3}$ are as follows: 7.3 to $9.4 ; 5.6$ to $7.4 ; 5.5$ to $8 ; 6.0$ to $9.5 ; 6-9$, respectively. All this data can be found in the review written by Kosmulski [11].

The polyphenol molecules were probably adsorbed onto iron particles and made the IEPs of GTnZVI much lower. The polyphenol molecule contains hydroxyl groups. These groups seem to strongly interact with nano-particles of iron. 
In a similar study, Yang [12] concluded that carboxymethylcelluloses (these molecules were used to stabilize iron nanoparticles) were adsorbed onto the nano-irons. These molecules resulted in the IEP of iron nano-particles being also lower.
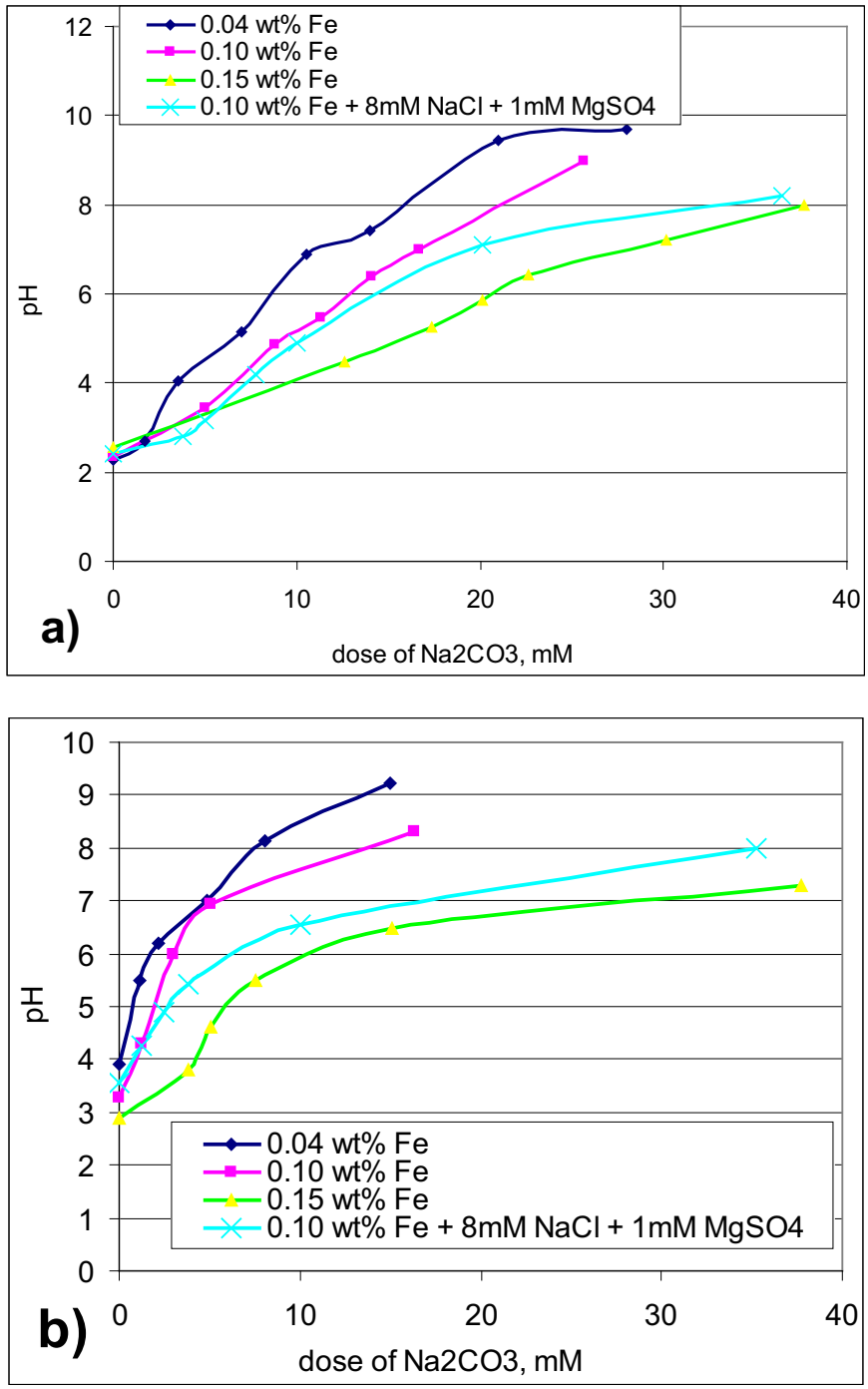

Figure 3. $\mathrm{pH}$ as a function of dose of $\mathrm{Na}_{2} \mathrm{CO}_{3}$ for a) GT- $\mathrm{nZVI}_{\mathrm{FeCl}}$ and b) GT- $\mathrm{nZVI} \mathrm{FeSO}_{\mathrm{F}}$.

As a result of $\mathrm{pH}$ increasing (see Fig. 3), the iron ions (not reduced earlier) have probably been precipitated out in the form of iron hydroxides, oxides or, in proper conditions, also in $\mathrm{Fe}(0)$ form. This, in turn, meant a decrease in the concentration of ions, thereby reducing conductivity in the initial stage of the addition of $\mathrm{Na}_{2} \mathrm{CO}_{3}$ - this was particularly evident for GT-nZVI $\mathrm{FeCl}_{2}$ (Fig. 4a). When more $\mathrm{Na}_{2} \mathrm{CO}_{3}$ was added, the loss of ions was compensated, and conductivity began to rise again (see Fig. 4). These phenomena have already been observed in the previous paper of the author [8].

In all tests, the ORP decreased significantly with an increase in the dose of $\mathrm{Na}_{2} \mathrm{CO}_{3}$, and thus, an increase pHs (Fig. 5). This can be associated with the precipitated iron compounds (iron hydroxides, 
oxides and $\mathrm{Fe}(0))$ that have a reducing property. In addition, higher values of $\mathrm{pH}$ also cause a lower ORP for the same reactions.
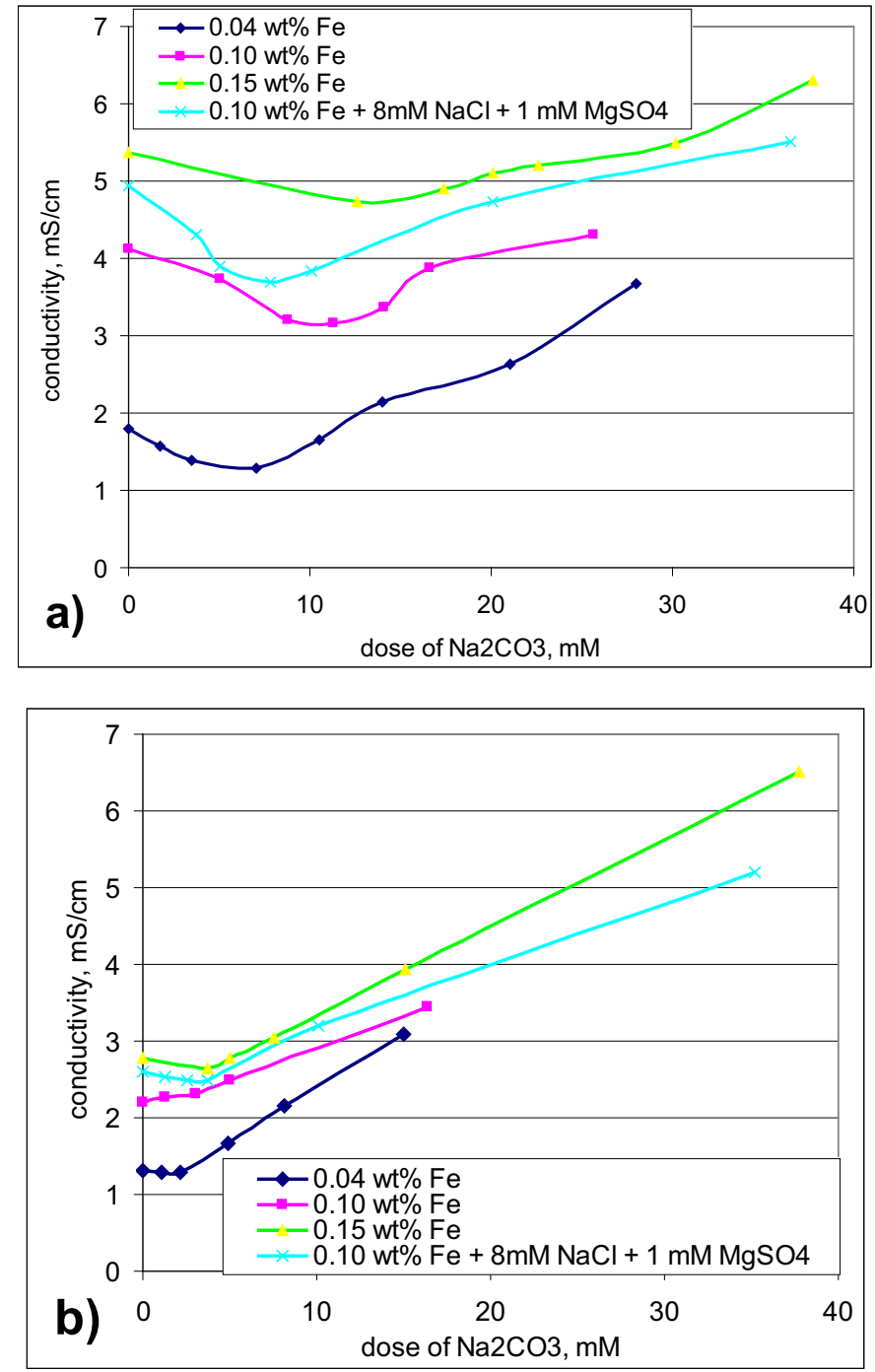

Figure 4. Conductivity as a function of dose of $\mathrm{Na}_{2} \mathrm{CO}_{3}$ for: a) GT- nZVI $\mathrm{FeCl}_{2}$, b) GT- nZVI $\mathrm{FeSO}_{4}$.

In both cases of nano-irons, other relationships were noted. The lower iron concentration in solutions for the preparation of GT-nZVIs, the lower the ORP, for a given dose of $\mathrm{Na}_{2} \mathrm{CO}_{3}$. Colloidal suspensions of GT-nZVI with a lower concentration of iron are characterized by higher values of $\mathrm{pHs}$ (see Fig. 3).

Based on the study, comparing the two colloids (GT-nZVI $\mathrm{FeCl}_{2}$ and GT-nZVI $\mathrm{FeSO}_{4}$ ), the GT$\mathrm{nZVI}_{\mathrm{FeCl} 2}$ was assessed as being more stable. For this suspension, the zeta potentials at $\mathrm{pH}$ above 7.5 were much lower than for GT-nZVI $\mathrm{FeSO}_{\text {. In addition, GT-nZVI }}$. values of ORP, which could be very important in assessing the reactivity of the material. However, in order to obtain $\mathrm{pH}$ above 7.5, a larger dose had to be added to get GT-nZVI $\mathrm{FeCl}_{2}$ than in the case of GT-nZVI ${ }_{\mathrm{FeSO} 4}$. 

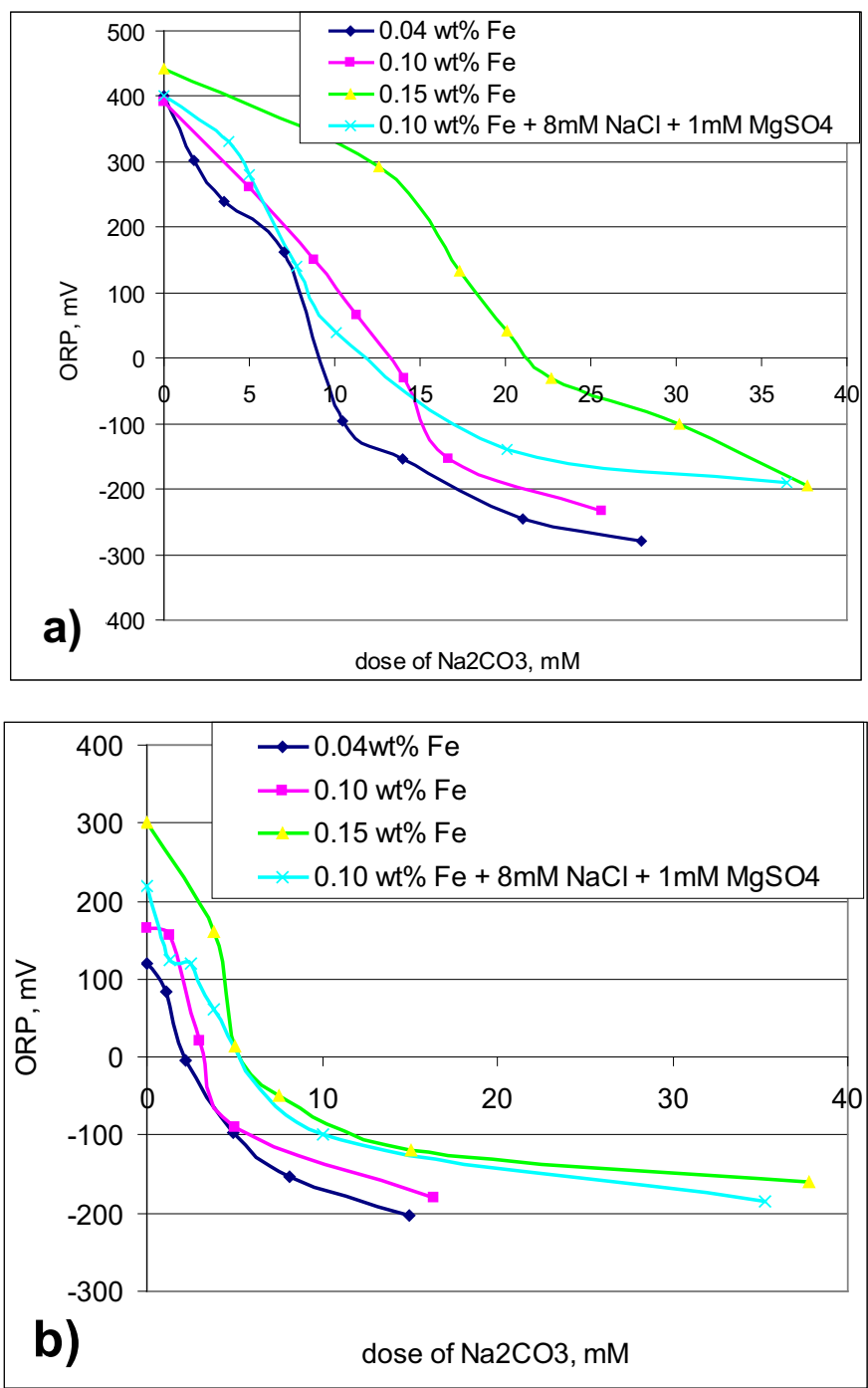

Figure 5. ORP as a function of dose $\mathrm{Na}_{2} \mathrm{CO}_{3}$ for: a) GT- nZVI $\mathrm{FeCl2}_{2}$, b) GT- nZVI $\mathrm{FeSO}_{\mathrm{F}}$.

Figure 6 presents the grain-size distribution of the particles in GT-nZVI $\mathrm{FeCl}_{2}$ at $\mathrm{pH}$ 7.5. The results indicate that the iron particles were in the range from 80 to $900 \mathrm{~nm}$, what means that they might create a colloidal suspension under the appropriate conditions. In the paper by Sun [10], the nano-irons, obtained by way of reduction of Fe(III) solution using a borohydride, had a size in the range from several to $900 \mathrm{~nm}$. The lack of particles with a size of several $\mathrm{nm}$ in the studies using GT, may be due to the fact that measurements were made after more than an hour after synthesis. At this time, the finest particles could be aggregated. 


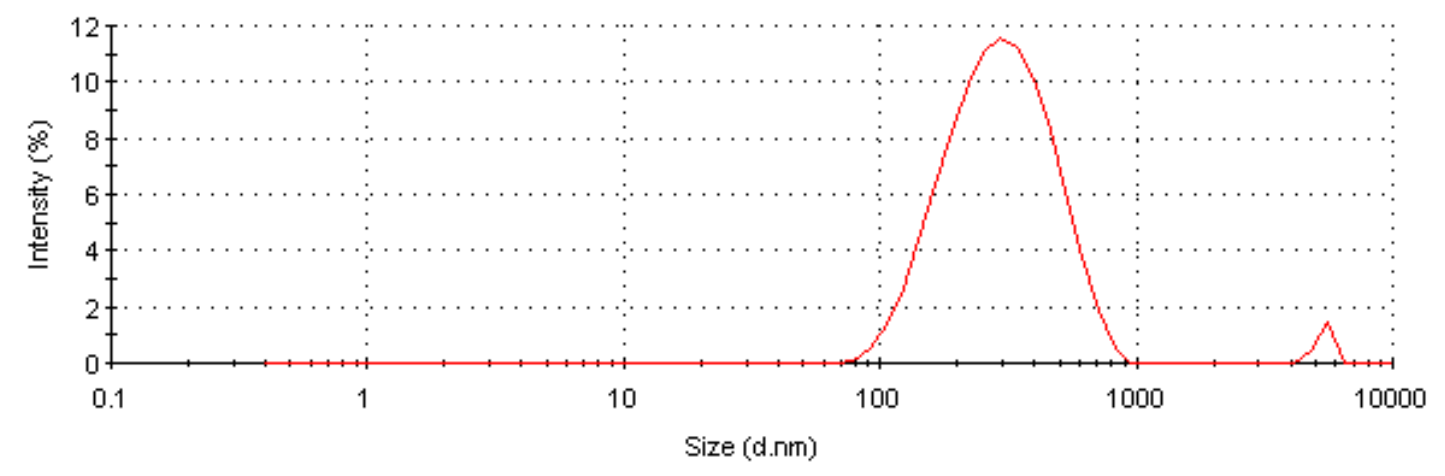

Figure 6. The grain-size distribution of the particles in $\mathrm{GT}-\mathrm{nZVI} \mathrm{FeCl}_{\mathrm{Fe}}$ at $\mathrm{pH}$ 7.5.

\section{Conclusions}

The suspensions of GT-nZVI, obtained as a result of mixing solutions of Fe(II) with a solution of green tea, were not stable. The particles of suspensions had a tendency to rapidly aggregate to form larger aggregates and then settled. The pHs of the suspensions were ca. 2.5 for GT-nZVI $\mathrm{FeCl}_{2}$ and between 2.9 and 3.9 for GT-nZVI $\mathrm{FeSO}_{\mathrm{F}}$, while the absolute values of zeta potentials were between 10 and $17 \mathrm{mV}$, and between 6 and $20 \mathrm{mV}$, respectively, for these suspensions. By adding $\mathrm{Na}_{2} \mathrm{CO}_{3}$, the $\mathrm{pHs}$ increased and consequently the absolute values of zeta potential increased and reached $45 \mathrm{mV}$ for

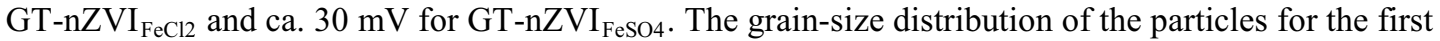
suspension, at a $\mathrm{pH}$ of 7.5, showed the particles were in the range from 80 to $900 \mathrm{~nm}$.

The isoelectric point of GT-nZVI $\mathrm{FeCl}_{2}$ was in the range from 4.5 to 5.0, while in the case of GT$\mathrm{nZVI}_{\mathrm{FeSO} 4}$ all the measured zeta potentials were negative. The addition of $\mathrm{NaCl}$ and $\mathrm{MgSO}_{4}$ to increase ionic strength, meant that in both of the suspensions the values of zeta potential were about $-25 \mathrm{mV}$.

\section{References}

1. V. Zolla, F.S. Freyria, R. Sethi, A. Di Molfetta, J. Environ. Qual., 38(3), 11 (2009)

2. W.X. Zhang, C.B. Wang, H.L. Lien, Catal. Today, 40(4), 8 (1998)

3. L. N. Shi, Y. Zhou, Z. Chen, M. Megharaj, R. Naidu, Environ. Sci. Pollut. Res., 20(6), 9 (2013)

4. T. Tosco, M. P. Papini, C. C. Viggi, R. Sethi, J. Clean. Prod., 77, 11 (2014)

5. M. N. Nadagouda, A. B. Castle, R. C. Murdock, S. M. Hussain, R. S. Varma, Green. Chem., 12(1), 8 (2010)

6. C. Mystrioti, N. Papassiopi, A. Xenidis, D. Dermatas. M. Chrysochoou, J. Hazard. Mater., 281, 6 (2015)

7. Y. Joshi, S. Khandekar, Nanoscale and microscale phenomena (Springer, 2015)

8. T. Suponik, Silesian University of Technology Monograph, 8, 11 (2016),

9. Y. Ji, Colloids Surf., A, 444, 8 (2014)

10. Y. P. Sun, X. Q. Li, J. Cao, W. X. Zhang, H. P. Wang, Adv. Colloid. Interfac., 120(1), 9 (2006)

11. M. Kosmulski, J. Colloid Interface Sci., 426, 4 (2014)

12. J. Yang, H. Sun, Water Air Soil Pollut., 226(9), 15 (2015) 